\title{
Editorial
}

\section{Bernhard Brüne}

\section{Happy Birthday: Biological Chemistry is celebrating its 400th volume}

https://doi.org/10.1515/hsz-2019-0389

The German scientist Felix Hoppe-Seyler established Physiological Chemistry as an independent academic discipline and made the important contribution of creating the journal Zeitschrift für Physiologische Chemie (Journal of Physiological Chemistry) in 1877, which he edited until his death in 1895. Subsequently, in 1896 the journal was renamed Hoppe-Seyler's Zeitschrift für Physiologische Chemie, and then became Biological Chemistry HoppeSeyler from 1985 to 1996. Since then the journal is known as Biological Chemistry.

Felix Hoppe-Seyler felt it was necessary to gather literature about physiological chemistry in one place, which made his journal the first specialized biochemical journal worldwide. Seminal observations published in the early days of the journal addressed research on globins, fermentation, redox-reactions, lipid metabolism as well as quantification and classification of proteins but also research on nucleic acids. In general it was the recognition of the importance of characterizing biological structures and processes in natural science and biomedicine.

The journal came a long way to cover all aspects of biochemistry with cross fertilization from areas of physiology, pharmacology and medicine. As a birthday present one often gets a nicely arranged bouquet of colorful and assorted flowers. This plurality reflects the wide spectrum of current biological research and consequently the rich variety of topics covered by Biological Chemistry these days, such as genes and nucleic acids, protein structure and function, membranes, lipids, glycobiology, molecular medicine, cell biology and signaling, proteolysis, and novel techniques. Papers from around the world, submitted by renowned scientists, filled many pages over the years and now allow us to publish the 400th birthday volume in 2019.

To celebrate the 400th volume of Biological Chemistry the journal would like to thank our authors, readers, referees and members of the editorial/managing teams. Their efforts helped to publish papers that reflect important and cutting edge science of modern biological chemistry. Contributions to this special issue are made by outstanding scientists that have served Biological Chemistry in the past and were asked to highlight topics in the tradition of its founder Felix Hoppe-Seyler to reflect important facets of the still vibrant area of physiological chemistry.

All the best to Biological Chemistry - may more exciting science be published in this journal and may the tradition of the first biochemical journal live forever.

\section{Bernhard Brüne}

Editor-in-Chief

Goethe-University Frankfurt

Faculty of Medicine

Institute of Biochemistry

Theodor-Stern-Kai 7

60590 Frankfurt, Germany

e-mail: b.bruene@biochem.uni-frankfurt.de 